\title{
BARRANCO Y MARAGALL: DOS DISCURSOS SOCIALISTAS
}

José Luis Blas Arroyo

\section{INTRODUCCIÓN}

El presente trabajo constituye un intento de aplicación de algunos de los métodos de análisis del discurso ideológico, desarrollados principalmente en Francia en los últimos tiempos, a dos textos españoles actuales. El corpus sobre el que hemos trabajado, lo forman dos intervenciones en un espacio electoral de T.V. de los candidatos socialistas a la alcaldía de Madrid y Barcelona, Juan Barranco y Pascual Maragall, respectivamente, con motivo de las elecciones municipales de junio de 1987. Como han señalado algunos lingüistas, el discurso político ofrece una serie de posibilidades idóneas para la aplicación de estos métodos sobre análisis discursivo cuya teorización está, no obstante, por hacer ${ }^{1}$. La recurrencia, caracteristica de estos textos, la distinción clara, frente a otros registros, entre enunciación y enunciado y otros hechos sobre los que no nos vamos a extender aqui, hacen que el analista pueda bucear en ellos con menos probabilidades de desaliento a la hora de determinar los mecanismos de generación del discurso. Y es por esta razón, lógicamente, por la que también nosotros hemos elegido un corpus típicamente político.

G. Provost señala en un artículo cuáles han sido los campos concretos de aplicación del análisis del discurso ideológico en los últimos veinte años ${ }^{2}$.

' L. Guespin, «Problématique des travaux sur le discours politique». Langage n." 23, Didier/Larousse, Paris, págs. 3 a 24.

. ' G. Provost, "Problèmes théoriques et méthodologiques en analyse du discours», Langue française n. ${ }^{\circ}$ 9. Larousse. Paris. págs. 6 a 21. 
En este sentido, distingue los estudios realizados sobre el corpus de un solo hablante, de aquellos otros donde el estudioso busca lo peculiar de un discurso frente a otro. En este segundo caso - Marcellesi, Maldidier, Courdesse, Guespin...- el trabajo realizado es claramente contrastivo. Como dice Marcellesi ${ }^{3}$, uno de los máximos representantes del análisis del discurso que desemboca en la sociolingüística, la tarea del investigador consiste en dar cuenta de las diferencias formales que caracterizan el discurso de cada grupo y que, eventualmente, pueden tener su correlato en las diferencias ideológicas. Sin embargo, el interés de éste debe ser fundamentalmente lingüístico, aunque a veces sea preciso acudir a la historia, a la psicologia o a la sociologia, para explicar las condiciones de producción que hacen posible el discurso. Por esta razón, puesta de manifiesto por varios lingüistas que ponen freno al excesivo optimismo de quienes ven una biunivocidad neta entre lengua e ideología, nuestro trabajo va a versar sobre dos secuencias ideológicamente afines. En ambos casos, se trata de hablantes socialistas que se dirigen a unos potenciales votantes, aunque esto no signifique una identidad en la estrategia de sus discursos. Así pues, nuestras conclusiones tendrán un carácter formal y lingüístico, cuyas diferencias difícilmente podrán ser asignadas a unas coordenadas políticas antagónicas.

Las hipótesis que queremos demostrar en el curso de estas páginas, se basan precisamente en esas distinciones formales entre ambos discursos. A nuestro juicio, el de Maragall es más directo que el del candidato a la alcaldía madrileña. El sentido de este adjetivo hay que entenderlo como una llamada electoral, principalmente dirigida a los votantes socialistas y que tiene como contrapartida la exclusividad en las valoraciones positivas de la gestión realizada. Frente a esta "claridad», el discurso de Barranco se articula de forma más sutil, incluyendo cuando es necesario, a otros votantes potenciales, a los que se asimila en la realización y en los «beneficios» de la acción socialista.

Para la confirmación de esta hipótesis, hemos utilizado fundamentalmente dos metodologías de las que actualmente se aplican en el análisis discursivo. En primer lugar, analizaremos el comportamiento de los actores de la enunciación, así como el de determinados elementos deícticos que les aparecen unidos. Este primer contacto tiene como objeto el integrarse posteriormente en un análisis sintáctico, distribucional, lo que Mainguenau llama análisis harrisiano lato. Con ello pretendemos obtener en ambos discursos una serie de oraciones básicas, que realizadas o no superficialmente, constituyan un modelo sobre el que se estructuran aquéllos. Para eso, hemos elegido algunos términos recurrentes, fuertemente correlacionados y que permiten acceder al «cuadro semántico» sobre el que se articula cada uno

"J. B. Marcellesi, "Elements pour une analyse contrastive du discours politique», Langage n. ${ }^{\circ}$, Didier/Larousse, Paris. págs. 25-56. 
de los textos. Eventualmente, asimismo, daremos cuenta de determinadas transformaciones que modalizan el discurso de alguno de los hablantes a partir de dichas oraciones base.

Una de las diferencias substanciales de este tipo de análisis, frente al de las gramáticas textuales o al harrisiano estricto, radica en la importancia concedida por el primero a la situación en que se produce el discurso, la comunicación. Esta situación, de la que forman parte no sólo la psicología del hablante, sino también la del oyente, así como factores sociológicos, históricos, etc., ha recibido diferentes nombres, pero hay uno con el que comúnmente es denominado: condiciones de producción. Este será pues el término que nosotros utilizaremos a partir de aquí, aunque en ocasiones acudamos a otros como contexto, situación de comunicación, etc. $Y$ precisamente comenzamos nuestro trabajo estableciendo las condiciones de producción que hacen posibles las dos secuencias discursivas elegidas. Al final del trabajo incluimos el corpus, transcrito de la grabación magnetofónica realizada en su día.

\section{Condiciones de Producción}

Como señala Mainguenau ${ }^{4}$, la teoria sobre la articulación entre el análisis del discurso y la descripción sociohistórica donde se integra éste, está todavia por hacer. Para algunos lingüistas, las condiciones de producción afectan exclusivamente a los factores individuales que ponen en relación, espacial y temporalmente, a los interlocutores, mientras que otros incluyen en ellas casi todo: el ambiente material, institucional, la psicología, etc. El principal problema estriba en determinar dónde acaba el dominio del lingüista y comienza el del historiador o el psicólogo, o dicho de otro modo, en averiguar qué es pertinente y qué no para el análisis del discurso.

Salvando esta inestabilidad, propia de los comienzos de una práctica reciente, nosotros vamos a incluir dentro de estas condiciones de producción, todos aquellos aspectos que, a nuestro juicio, son importantes para la generación de nuestras secuencias discursivas. Así pues, aludiremos a la situación extralingüistica en la que se produce la comunicación entre el hablante y sus interlocutores. Asimismo, veremos también la importancia del intertexto, es decir, la remisión a otros discursos que forman paradigma con éstos y que ideológicamente pueden o no ser afines ${ }^{5}$. Otros factores de in-

4 D. Maingueneau, Iniciación a los métodos del análisis del discurso. Hachette Argentina, Buenos Aires, 1981.

'J. Courtine, Quelques problèmes théoriques et méthodologiques en analyse du discours à propos du discours communiste adressé aux chrétiens. Thèse de doctorat de 3ème cycle de Linguistique, Paris X, Nanterre, 1980. 
terés, por último, son las llamadas formaciones imaginarias ${ }^{6}$ por las que hablante y destinatario adoptan determinados papeles (roles, estatus...) que los ubican en la situación de comunicación.

Como ya hemos dicho, nuestros dos discursos constituyen sendas intervenciones de los candidatos socialistas a las alcaldías de Madrid y Barcelona en un espacio electoral gratuito de TVE. La situación histórica en la que ambos se producen es la de unas elecciones municipales, que en el caso de las de junio de 1987, iban acompañadas por las de los parlamentos autonómicos y europeo. Esta triple elección hacía que, a tan sólo un año de las generales de 1986, donde el partido socialista triunfó por segunda vez consecutiva consiguiendo la mayoría absoluta, las expectativas y el interés de las distintas formaciones políticas fueran muy altos. Algún político, como el presidente de Alianza Popular, Antonio Hernández Mancha, las había considerado, en una de sus intervenciones públicas, como la antesala de unas elecciones legislativas anticipadas, a la vista del esperado fracaso estrepitoso del partido en el Gobierno. Los sondeos habían dado unos resultados preocupantes para el PSOE, que perdía la mayoría absoluta en muchas de las ciudades y comunidades autónomas donde hasta ahora gobernaba de forma holgada. Y todo ello en beneficio de un grupo político, el CDS, que de la mano de Adolfo Suárez, había visto multiplicar sus posibilidades en las pasadas elecciones y que ahora se constituía en una peligrosa tercera formación política, imprescindible a la hora de establecer pactos electorales. Estos hechos hicieron que, durante la campaña electoral, se intensificaran las críticas de todos los grupos políticos hacia el PSOE, desde el centro-derecha (AP, CDS, CIU...) hasta la izquierda (IU...). Estas críticas ponían el acento en la arrogancia de los gobernantes, en sus despilfarros a la hora de gastar el dinero de todos en obras destinadas más a la galería que a solucionar los verdaderos problemas municipales.

Algunas de estas coordenadas históricas tienen una indudable importancia para la comprensión de nuestros discursos. Los textos de Barranco y Maragall tienen un claro matiz propagandístico, pues ambos se basan en los logros conseguidos por sus administraciones en los últimos años. Aunque de forma diferente, como veremos, los dos candidatos ponen el énfasis en las obras hechas y proyectadas, que se pretenden de una indudable importancia para el desarrollo de Madrid y Barcelona, haciendo frente, así, a las críticas de despilfarro y déficit ${ }^{7}$. Por otro lado, ni Barranco ni Maragall se enfrentan explícitamente a otras formaciones políticas y ello por una razón evidente: el poder municipal de ambas ciudades, desde la restauración de la democracia, ha recaído durante los últimos ocho años en el PSOE.

\footnotetext{
- M. Pécheux, L'analyse automatique du discours, Dunot, 1969, pág. 18.

7 Barranco, por ejemplo, menciona que por primera vez en la historia del ayuntamiento madrileño se ha conseguido todo eso sin déficit.
} 
No obstante, sí hay una alusión en ambos casos, al contraste entre la actual situación y la de los gobiernos nefastos de los tiempos franquistas. En conclusión, el discurso de los candidatos socialistas no puede entenderse sino en el seno intertextual ya mencionado, esto es, el conjunto de discursos que en unas mismas coordenadas históricas mantienen una relación paradigmática entre sí, ya sea porque se inscriben dentro de una ideología afin, ya por el contrario.

Otro factor situacional importante entre las condiciones de producción es el canal de comunicación elegido. En efecto, recordemos que no estamos ante un mítin político donde el hablante se dirige directamente a los oyentes, con los que mantiene una relación estrecha hasta el punto de que la reacción - positiva o negativa - de éstos, puede llevar a modificar sobre la marcha la estructura del discurso. Por el contrario, nos encontramos aquí ante dos secuencias que se integran dentro de un espacio televisivo, con la importancia decisiva del elemento visual. Ésta, junto a una premeditada y cuidada preparación del discurso oral, son las dos marcas más relevantes del mismo, asi como lo que lo distingue de la intervención pública ante un auditorio presente. Es importante mencionar que el espacio electoral fue repartido en diversas intervenciones alternantes de Barranco y de Maragall, de manera que a una secuencia del primero sucedía otra del segundo y así sucesivamente. Asimismo, es preciso tener presente el carácter y contenido de cada una de estas intervenciones; se empieza generalmente por el recuerdo de los cuatro años pasados, sigue el recuento de las realizaciones materiales conseguidas y se concluye por los proyectos en marcha o futuros, para cuya conclusión se pide el voto. Por lo que se refiere al escenario visual, destaquemos la diferencia existente entre el aire «apacible» que rodea a Barranco -aparece en su despacho de la alcaldía madrileña; otra vez junto al río Manzanares, supuestamente «regenerado»- y el ruido urbano en el que aparece Maragall, quien habla desde la calle en todo momento. Lo anterior nos lleva a considerar también al conjunto de los programas electorales que, en los distintos medios de comunicación y principalmente TVE, dispusieron los partidos políticos para su propaganda. En ellos, destacaron por parte de las formaciones rivales, las críticas casi unánimes a los socialistas, que incidian, según las ideologías, en torno a los distintos aspectos del gobierno municipal. Por su parte, los candidatos socialistas ponían el énfasis, al igual que Barranco y Maragall, en los logros conseguidos por personas honradas y progresistas.

El concepto de "formaciones imaginarias", mencionado anteriormente, tiene también su importancia en este capitulo. Por él se entienden los específicos "roles", adoptados tanto por hablante como por destinatario, y que en el caso del discurso político, tienen una gran relevancia. En los discursos de Barranco y Maragall, esa distancia entre ambos es apreciable. Los dos son candidatos a la alcadia, y como tales, se dirigen a un electorado potencial a quien intentan convencer. No obstante, como veremos, la opo- 
sición ciudadano-candidato está más marcada en el caso de Maragall que en el de Barranco, quien intenta asimilarse a la ciudadanía, asi como hacerla participe directa del gobierno municipal. Asimismo, hay que subrayar que durante esta campaña electoral el "estatus» de ambos candidatos ofrecía también diferencias de interés. Mientras Maragall asumía plenamente su condición de aspirante perfectamente cualificado por su formación intelectual y profesional, Barranco se presentaba - con muchas dudas por parte del electorado, que lo asimilaba al eficiente concejal pero escasamente digno sucesor de Tierno Galván - como el primer candidato a la alcaldía madrileña de formación no universitaria. Esta condición, que sin duda suponía una contradicción con el prototipo de político de altos vuelos, debía ser contrarrestada mediante la asunción de otros papeles ante el electorado. Esto explica, a nuestro juicio, el tono retórico mantenido a lo largo de todo su discurso, donde se conjugan el recuerdo de una tradición populista y el recurso a la redundancia como artificio estilístico, frente a un Maragall bastante más «liso y llano». A nuestro juicio, esta distinción entre los papeles asumidos implícitamente por los dos candidatos tiene su traducción, como luego intentaremos demostrar, en la idiosincrasia de cada discurso. En cualquiera de los casos, y a pesar de determinadas diferencias en cuanto a las condiciones de producción entre ambas secuencias discursivas, creemos que los dos textos aparecen como bastante "homogéneos». Por lo tanto, consideramos que un análisis contrastivo puede ser realizado sin riesgo de incorrecciones enojosas de partida.

\section{Sujeto y Destinatario en el Proceso de Enunciación}

Siguiendo a Benveniste ${ }^{8}$, podemos distinguir en todo texto el enunciado de la enunciación, por lo cual el hablante "maneja la lengua por su cuenta», «toma la lengua por instrumento». En este sentido, dice Benveniste, la aparición de índices personales (en pronombres, formas verbales...) sólo se produce por la enunciación, y así son fácilmente distinguibles discursos como el pedagógico o el científico, donde el sujeto de enunciación está enmascarado bajo la tercera persona (no-persona) del enunciado; del discurso polémico, o por lo que aquí nos interesa, del discurso político, donde el emisor de la comunicación, así como el destinatario, emergen claramente. Por lo que hace a nuestros dos discursos, estos caracteres aparecen constantemente, y así tanto Maragall como Barranco surgen como sujetos de

" E. Benveniste, Problemas de Lingüistica general, Méjico, Siglo XXI, 1971. 
enunciación, ya individual, ya colectivo ${ }^{9}$. Pero vayamos por partes y analicemos por separado cada caso.

A nuestro juicio, y a pesar de que tanto Barranco como Maragall utilizan mayoritariamente el "nosotros», sujeto colectivo de enunciación -pues ambos pertenecen a un grupo político en cuya lista se presentan a la elección-, las diferencias en cuanto a su contenido son importantes. En el discurso del candidato madrileño, hay un deslizamiento continuo entre el «nosotros = socialistas» y el "nosotros = madrileños (todos)». En ocasiones, esta distinción aparece neutralizada, lo que constituye una sutil maniobra para incluir a la colectividad (o al menos a una inmensa mayoría) dentro de la familia socialista, o por lo menos en acuerdo sustancial con ella.

En su intervención central, aquella en la que ambos candidatos presentan los logros conseguidos en los últimos años, el «nosotros» es sinónimo, claramente, de "socialistas»: «De los 50.000 millones que hemos invertido en obra nueva...", "y con una labor que queremos continuar a partir de este año 1987». En ocasiones, es el posesivo "nuestro» el introductor de este sujeto de enunciación socialista: "se puede apreciar esta obra, este fruto de nuestra gestión». Aun así, e incluso en esta secuencia central, a veces el sujeto de enunciación se encubre bajo una aparente impersonalidad, cuando se habla de las realizaciones pasadas y futuras: "ahí está también a la vista de todo el mundo el esfuerzo de gestión que se ha hecho en los últimos cuatro años (...) una gestión que se ha hecho en los últimos años, por primera vez en la historia de nuestro ayuntamiento, sin déficit.»

Este deslizamiento hacia un "nosotros» colectivo, y no solamente socialista, está todavía más claro en las secciones primera y tercera, más retóricas en su conjunto. Así, el candidato madrileño comienza su alocución apelando a la recuperación «de nuestra memoría histórica, de nuestras costumbres, de nuestras raíces, y de las fachadas del Madrid de los Austrias...". Más adelante, afirma que «esa rehabilitación nos ha llevado a que en estos momentos ostentemos la presidencia de la unión de capitales europeas». Asimismo, al final alude a que en 1992 unos vamos a convertir en el gran escenario (...) de la cultura mundial».

Pero, como hemos dicho más arriba, muchas veces se produce una neutralización entre esos dos valores del "nosotros» (madrileños y socialistas) en favor de estos últimos, de manera que el espejismo se desvela claramente en secuencias propagandísticas como: «este es el Madrid por el que estamos trabajando todos», "este es el Madrid que queremos.» El intento de asimilar el proyecto socialista al conjunto de la sociedad está muy claro en estas frases, como también cuando Barranco afirma que las obras realizadas y los proyectos futuros «nos permiten asegurar con confianza que esta ciudad

๑ J. B. Marcellesi, Introducción a la sociolingüistica, Madrid, Gredos, 1979. 
tiene un futuro formidable». O en su despedida, «Para que todos los vecinos el día de mañana podamos sentirnos legítimamente orgullosos de haber construido una ciudad más próspera». ¿Quiénes podemos asegurar ese futuro? ¿Quiénes estaremos orgullosos? TODOS - y ésa es una de las palabras «clave» en el discurso de Barranco-..., pero gracias a «nosotros los socialistas".

En resumen, el esquema de utilización del «nosotros", como sujeto de enunciación, es bastante simétrico. Abre y cierra su discurso propagandístico incluyéndose en una colectividad de ciudadanos de la que se siente orgulloso y «corresponsable». Pero esa ciudadanía o la mayor parte, comparte con los socialistas el modelo de ciudad que desea, y por eso, en un breve espacio central, se da entrada a la voz de estos últimos.

El sujeto de enunciación colectivo, mayoritario en los dos discursos, es completado, también en ambos, por un "yo» individual, que tiene la función de rubricar la seguridad del candidato en el proyecto colectivo socialista en el que está inmerso: "Yo creo que con mirar las cosas con serenidad...», "Y ésta es la gran ilusión y la gran confianza que yo quiero transmitirles a todos ustedes». En el discurso de Maragall, este sujeto individual de carácter confirmativo, aparece también en tres ocasiones. Y en todas ellas lo hace acompañando al verbo "creer», que aporta esa modalidad de certidumbre ${ }^{10}$.

Pero el uso del sujeto colectivo de enunciación, tiene en éste unos caracteres marcadamente diferenciados respecto a los ya vistos en el discurso de Barranco. Para generalizar, diremos que en la intervención de Maragall, «nosotros» tiene casi unilateralmente el valor de «socialistas». Así como en el texto anterior alternan la impersonalidad y el «nosotros» a la hora de narrar los logros obtenidos, Maragall comienza con una pasiva refleja («creo modestamente que en esta ciudad se están haciendo cosas ejemplares»), para pasar inmediatamente después a una larga serie de enunciados donde emerge claramente este "nosotros = socialistas» como sujeto de enunciación. Y lo mismo ocurre en su última intervención, la de carácter más institucional y retórico. Aunque comienza, como Barranco, con una alusión a "nuestras tradiciones", que engloban a toda la sociedad, pasa a continuación a subrayar que hemos sido nosotros quienes hemos trabajado para recuperarlas ${ }^{11}$. Y su despedida, aparentemente idéntica a la de Barranco, donde se proyectan hacia el futuro las ilusiones para el progreso de la ciudad, no deja lugar a dudas, pues se confunde con el lema del PSOE durante esta campaña: «Haciendo las cosas bien hechas, ganaremos el futuro» (y lo conseguiremos "nosotros, los socialistas»).

El interés de estas diferencias en cuanto al valor de los sujetos colectivos de enunciación, se ve confirmado también si observamos el del destinatario

${ }^{10}$ D. Maingueneau, Op. Cit. Pag. 127.

"El subrayado y la cita son nuestros. 
de la comunicación, los posibles votantes. Así, el candidato madrileño, apela directamente a los ciudadanos, a quienes intenta hacer reflexionar con serenidad y objetividad sobre el presente y el futuro de su ciudad. Para ello, oscila entre el enmascaramiento del receptor en una especie de impersonalidad globalizadora: "yo creo que... se puede apreciar esa obra, ese trabajo... ese fruto de nuestra gestión que está a la vista de todos aquellos hombres... que quieran reflexionar y ver la realidad con objetividad». Pero también en el final de su discurso apela directamente a aquél, mediante el pronombre de respeto «ustedes»: "Y lo que me gustaría transmitirles, lo que me gustaría contagiarles a todos ustedes...». Un "ustedes», como estamos viendo, que vale tanto para los afiliados y simpatizantes socialistas, como para todos aquellos madrileños de buena voluntad que no se dejen engañar por la falta de objetividad.

Por el contrario, nuevamente el discurso de Maragall se nos ofrece más partidista. Sólo en una ocasión se menciona bajo la tercera persona a los ciudadanos ("yo creo que trabajando juntos, ciudadanos y ayuntamiento, lo conseguiremos»). Y ello porque, como hemos dicho, el discurso de $\mathrm{Ma}$ ragall se manifiesta más orgulloso y seguro de las realizaciones socialistas. Y quizá por esta razón, no es tan necesario apelar directamente a unos votantes que por otro lado, se suponen ya perfectamente delimitados.

\section{LA DeIXIS}

En el presente capítulo, analizaremos el empleo de algunos deícticos (demostrativos y algunos adverbios de lugar) también como marcadores de la enunciación. A partir de ellos, y sobre todo en el discurso de Juan Barranco, intentaremos obtener, en algunas de las secuencias discursivas, alguna oración base, que dé cuenta de su proceso de formación.

En su primera intervención, Barranco articula el discurso mediante la oposición clara de dos actualizadores demostrativos (aquella/este), representativos de la situación de la ciudad anterior al socialismo y la actual: "Aquella situación... este Madrid». Un análisis distribucional de esta secuencia nos permite hallar una serie de clases de equivalencias sintácticas, pero también semánticas, a partir de las cuales se estructura el discurso. En la columna de «aquella», figuran sustantivos semánticamente «negativos» como: desidia, abandono, deterioro, especulación.

Del lado de «este», por el contrario, encontramos dos términos «clave»: recuperación y rehabilitación. A su vez, estos sintagmas nominales, que forman una clase de equivalencias, son expansionados por una serie de sintagmas preposicionales que especifican su carácter. Así, tenemos «de recuperación de nuestra memoria histórica, de nuestras costumbres, de nues- 
tras raíces...», pero también "de recuperación y de rehabilitación de las casas y de las fachadas del Madrid de los Austrias...». Esto nos lleva ante nuevas clases: «nuestra tradición (el Madrid de los Austrias, de Galdós, etc.)» «este Madrid (actual)».

A partir de esta sarta de equivalencias, se puede llegar, como dijimos, a una oración básica que, mediante una serie de transformaciones, da lugar a las distintas frases de superficie. A nuestro juicio, la oración base que corresponde a esta primera secuencia discursiva, estaría próxima a la siguiente ${ }^{12}$.

Esta situación $Y$ (que coincide con nuestra tradición ha sustituido a aquella situación $\mathrm{X}$, gracias a $\mathrm{Z}$ (nosotros). Es interesante observar ahora cómo Barranco utiliza una transformación de pasivización a partir de aquí. De esta manera, podemos decir que se tematiza $a^{13}$, al colocarse en primer lugar, ese referente pasado e indeseable, a la vez que se pone el énfasis sobre el «agente» que ha cambiado esa situación y sobre quien se cristaliza lo esencial de la información: "aquella situación... ha sido sustituida por una política de respeto...» (no otra, y que además es la nuestra).

Siguiendo con el problema de la deixis, digamos que en el discurso de Barranco vuelven a aparecer posteriormente nuevas y abundantes muestras. Por ejemplo, en la secuencia central, la dedicada al relato de las realizaciones, cada una de éstas aparece señalada» mediante el adverbio "ahí»: "ahí está, por ejemplo, este río Manzanares...», «ahí está también, a la vista de todo el mundo, el esfuerzo que se ha hecho... los cincuenta mil millones en obra nueva... Más de cuarenta centros para la tercera edad y para la juventud...). Con ello, el candidato intenta distanciarse en su apreciación de los logros obtenidos y deja que sean los propios madrileños quienes, de una forma objetiva, lo confirmen. El «ahí», frente al "aquí» o «allí, intensifica ese deseo de serenidad y reflexión que parece destilar el discurso de Barranco. Idéntico significado tiene, más abajo, el demostrativo «ese»: «se puede apreciar esa obra, ese trabajo, ese fruto...».

Lo anterior se vuelve a poner de manifiesto en la última parte de su discurso, cuando el candidato a la alcaldía apela directamente a los ciudadanos. Esta es la esperanza de Barranco por el porvenir de Madrid, la que desea transmitir y compartir con aquellos: "Y ésta es la gran ilusión y la gran confianza que yo quiero transmitirles a todos ustedes».

En menos ocasiones, el empleo de los deícticos tiene una simple función señalizadora en el espacio o en el tiempo (no olvidemos que estamos ante un espacio televisivo y que la palabra y la imagen se superponen): «este río

12 Recordemos el carácter abstracto y no realizado del que hablan los lingüistas para muchas de éstas.

${ }_{13}$ M. A. K. Halliday, "Notes on transitivity and theme». Journal of linguistics, III-1, III2, IV-2, (1967-68). 
Manzanares, limpio, sano, recobrado...», «en ese año (1992), nos vamos a convertir en el escenario...».

Este sentido locativo es el que domina, por el contrario, en el discurso de Pascual Maragall. Como en el caso de Barranco, también aquel se refiere a "esta ciudad", pero aqui no tiene un sentido nocional, histórico, como alli. Por el contrario, se trata de la referencia a un objeto que está presente, justo a la vista del hablante. Esto explica el que Maragall emplee el adverbio de lugar "aquí» (frente al "ahí) de Barranco) que señala en el espacio publicitario al lugar donde se sitúa el candidato (un puente, en pleno puerto de Barcelona): "Aquí debajo mismo, vamos a hacer pasar el cinturón litoral...». En otra ocasión, por el contrario, dicho adverbio tiene una significación más amplia. Así, en: «Se trabaja aquí con imaginación», se alude claramente a la ciudad de Barcelona. En cualquier caso, la pobreza deictica en el discurso de Maragall es significativa frente a todo lo contrario en el de Barranco. En el capítulo final, veremos cómo se pueden integrar estas conclusiones en el marco de la formación discursiva.

\section{TIEMPO Y ASPECTO VERBALES}

El discurso de Maragall se articula claramente en torno a lo ya realizado por un lado y a aquello que falta por hacer, por otro. Esto se traduce en el empleo de un número concreto de formas verbales que expresan un tiempo pasado, presente o futuro, - según los casos-, a la vez que un aspecto imperfectivo siempre. Con ello, el candidato socialista enlaza los logros ya realizados con aquellos que se están consiguiendo en el presente y continuarán más adelante, todos ellos bajo la órbita socialista. De esta manera, se hace ver que la labor emprendida está en curso y, para completarla, se solicita nuevamente la confianza del electorado.

Por lo que se refiere al tiempo pasado, destaca en el discurso de Maragall el empleo de formas compuestas como verbo auxiliar de un gerundio, esto es, perífrasis de aspecto continuativo: «nosotros, en los últimos años, hemos estado trabajando para que esta tradición...». "Y creo que lo hemos estado consiguiendo, como otras ciudades españolas también lo están consiguiendo». Otras veces, como hemos dicho, la perífrasis de gerundio con verbo auxiliar simple, traduce las realizaciones conseguidas día a día y que, por tanto, tienen una repercusión en el presente: «en esta ciudad se están haciendo cosas ejemplares». "Estamos ganando terreno para la ciudad, recuperando las antiguas instalaciones ferroviarias...».

En el otro extremo, los proyectos futuros son expresados mediante dos formas: la perifrasis «ir a + infinitivo» y la forma sintética en - ré. Cada una de ellas tiene a su vez un valor propio; así, en el capítulo de "promesas" 
concretas, Maragall emplea en todos los casos la perífrasis, quizá porque su proverbial valor de futuro inmediato la hace más apta. El futuro imperfecto colocaria dichos proyectos en un porvenir demasiado indeterminado: «Aquí debajo mismo, vamos a hacer pasar el cinturón litoral, que junto con el segundo cinturón...». «En el corazón de la ciudad... vamos a construir la Casa de la Caridad, el Museo de Arte Contemporaneo...»

Por el contrario, el candidato socialista acude al futuro imperfecto en sus dos últimas oraciones, la de mayor carácter electoralista y propagandístico: "Yo creo que trabajando juntos, ciudadanos y ayuntamiento, lo conseguiremos. Haciendo las cosas bien hechas ganaremos el futuror.

También en este capítulo relativo al tiempo y aspecto de las formas verbales, hallamos diferencias entre ambos discursos. Así, Barranco emplea en el suyo perífrasis continuativas de gerundio, pero en un número de casos considerablemente menor («Éste es el Madrid por el que estamos trabajando»). Por el contrario, el candidato madrileño distingue más claramente las empresas ya concluidas y el porvenir, lo que se traduce en el predominio de las formas compuestas cuando la mirada se vuelve hacia el pasado: «Este Madrid, que ha merecido la atención y el respeto...». «Este Madrid que nos ha llevado, gracias al prestigio internacional...».

Como vemos por los ejemplos anteriores -lo que es extensible, por otro lado, a todo su discurso-, Barranco pone el énfasis en el cambio profundo ya experimentado en el transcurso de los últimos ocho años, desde que la democracia y los socialistas llegaron al ayuntamiento madrileño. Es lógico pensar que también en el espíritu de las palabras de Maragall emerge este mismo sentimiento, pero en su discurso, la referencia al pasado es menor y por consiguiente, la oposición entre éste y el momento presente tiene también un menor valor.

El tiempo presente ofrece asimismo matices interesantes en el discurso de Barranco. Por un lado, éste lo emplea al reflexionar desde la perspectiva actual acerca de la transformación de la ciudad en los últimos años e invita, como ya hemos visto, a hacerlo a los madrileños de buena voluntad. Pero también cuando esa reflexión se dirige hacia el porvenir de Madrid. Es importante observar cómo en este discurso no aparece la forma en «-ré» para la expresión de futuro. Al igual que antes, aparece en varias ocasiones la perifrasis «irá + infinitivo»: "Madrid quiere ser y va a ser en 1992, la capital...», «en ese año nos vamos a convertir en el gran escenario, no sólo de la cultura...». Observemos en la primera frase el empleo de la perifrasis «querer + infinitivo» como expresión de futuridad, con un claro valor modal, el mismo que encontramos en otras o en el mismo presente de indicativo: el futuro de la ciudad es enfocado por el candidato madrileño desde una perspectiva claramente voluntaria. Ya no hay la seguridad del futuro sintético, sino la voluntad, el deseo de conseguirlo con el esfuerzo de todos: «Este es el Madrid que queremos», "para que el día de mañana podamos sentirnos legítimamente orgullosos...» 
Como ya vimos anteriormente, en el discurso de Juan Barranco, el sujeto colectivo de enunciación, "nosotros", suele encubrir con frecuencia al simple referente socialista para crear en el electorado la ilusión de un agente colectivo en el que pueda sentirse incluido. Asimismo, mencionamos que este hecho aparece íntimamente relacionado con el empleo frecuente del cuantificador "todos». Este, junto a los otros datos ya analizados, nos permitirán obtener esas oraciones básicas que articulan los discursos. En las líneas siguientes, veremos el comportamiento sintáctico y semántico de este término en algunas de las secuencias discursivas donde aparece.

Sólo en una ocasión funciona "todos» como núcleo, mientras que en todos los demás casos aparece como un prearticulo, modificador directo del nombre: «éste es el Madrid por el que estamos trabajando todos" / «Está a la vista de todo el mundo el esfuerzo de gestión que se ha hecho en los últimos cuatro años».

Por otro lado, y a pesar de la variedad funcional de superficie de los sintagmas donde aparece (complementos indirectos, circunstanciales, del nombre, etc.), las funciones semánticas de éstos son mucho más concretas. Por utilizar una terminología característica de la gramática de casos ${ }^{14}$, digamos que en ocasiones remiten a un Dativo o Benefactivo, es decir, el destinatario de la acción verbal realizada por el agente. Veamos algunos ejemplos:

\footnotetext{
Una riqueza de la que nos vamos a beneficiar todos los madrileños, todos los barrios, todos los distritos de Madrid. Aquí está... ese río Manzanares... recuperado... para todos los madrileños.

Más de cuarenta centros para el disfrute de todos los madrileños, en todos los barrios $y$ en todos los distritos.
}

Otras veces, por el contrario, y aquí radica lo más interesante, nos hallamos ante un caso Agente, donde es por lo tanto, toda la sociedad, todos los madrileños los realizadores del progreso de su ciudad. Esto se ve muy claro en el ejemplo anterior:

${ }^{14} \mathrm{Ch}$. J. Fillmore, "Linguistics as a tool for discourse analysis", Van Dijk, Handbook of discourse analysis, vol. I, págs. 11 a 40. 
Este es el Madrid por el que estamos trabajando todos.

Pero también en las frases siguientes:

\begin{abstract}
Y esa confianza para que todos los madrileños participen en la construcción del futuro de la ciudad de Madrid. Para que todos los vecinos, el día de mañana, podamos sentirnos legítimamente orgullosos de haber construido una ciudad más próspera, una ciudad más joven, una ciudad para la convivencia, y sobre todo, una ciudad para la paz.
\end{abstract}

En definitiva, el conjunto de los madrileños, bajo la forma del indefinido «Todos», aparece para el hablante como el beneficiario de las acciones socialistas, como no podia ser de otro modo dado el carácter electoralista del discurso. Pero también se le hace creer a esa colectividad que está participando directamente y lo va a seguir haciendo, en la consecución de su propio futuro.

Frente a esta actitud de Barranco, el discurso de Maragall vuelve a ser menos retórico, menos conciliador. En sólo una ocasión, aparece «todos» como núcleo de un sintagma nominal cuya referencia, además, no está claro que designe exclusivamente a los barceloneses: "Ya luego en el Ensanche, que todos conocen, estamos consiguiendo la nueva frontera...". A nuestro juicio, en la secuencia anterior hay una cierta gramaticalización que establece una referencia más amplia que la de los simples receptores naturales (los electores de Barcelona). Aquí sería sinónimo —creemos- de «como todo el mundo conoce...".

Asimismo, es interesante observar que, en la única ocasión en que Maragall invita a los ciudadanos a trabajar junto al Ayuntamiento en la construcción de Barcelona, no emplea este término integrador: "Yo creo que trabajando juntos, ciudadanos y ayuntamiento, lo conseguiremos». Obsérvese de paso cómo la simple separación en dos compartimentos diferentes -aunque no aislados - entre ciudadanía y corporación municipal, hace pensar que, al menos aparentemente, Maragall cree verdaderamente en la democracia representativa.

\title{
CONCLUSIONES
}

A la vista de los datos analizados en este trabajo, creemos poder expresar a continuación cuáles son las estructuras profundas que subyacen en ambos 
discursos socialistas. Siguiendo, como hemos dicho, el método de análisis harrisiano lato, por el que se extraen una o varias oraciones base que dan cuenta del proceso de formación del discurso, éstas podrían ser las dos que estructuran el texto de Maragall:

$$
\begin{aligned}
& \mathrm{X} \text { (nosotros }=\text { socialistas) estamos haciendo } \mathrm{Y} \text {. } \\
& \mathrm{X} \text { (nosotros }=\text { socialistas) vamos a hacer } \mathrm{Z} .
\end{aligned}
$$

A través de estas dos frases básicas, observamos claramente la división entre las referencias al pasado y presente por un lado, y al futuro por otro, que se corresponden con otras tantas intervenciones en el espacio electoral. Asimismo y en ambas, hallamos ese sujeto colectivo de enunciación que remite a los socialistas en todo momento, pues son ellos quienes han hecho y piensan seguir haciendo progresar $(Y, Z)$ a la ciudad. En definitiva, y aunque en ningún momento se utilice el apelativo "socialista", el discurso de Maragall es más partidista, esto es, está enfocado desde una óptica de partido clara, posee una estructura propagandística definida y destinada fundamentalmente a los votantes convencidos.

Por el contrario, el discurso de Barranco es más complejo, y esta complejidad la traducimos nosotros en tres oraciones básicas:

$\mathrm{X}$ (nosotros $=$ socialistas, a veces también $=$ todos $)$ hemos hecho.

Y para Z (todos).

$Z$ (todos) pueden comprobar $Y$.

$X$ (nosotros $=$ socialistas; $a$ veces también $=$ todos) vamos a hacer $Y^{\prime}$ para $Z$ (todos).

Las principales diferencias con el discurso anterior se refieren al sujeto colectivo de enunciación y a la presencia constante de un destinatario a quien aquél se dirige. Este destinatario son todos los madrileños, quienes además de beneficiarios de las realizaciones socialistas, se convierten a veces también en los propios agentes de su progreso social. Y así, la promesa de lo que los socialistas harán en el futuro tiene su mayor garante en el hecho de que TODOS pueden comprobar que lo dicho es verdad.

\section{TRANSCRIPCIÓN DE LOS DISCURSOS}

Incluimos a continuación la transcripición íntegra de los discursos electorales de Juan Barranco y Pascual Maragall. Ambos han sido recogidos 
mediante grabación magnetofónica de un espacio electoral emitido por TVE con motivo de las elecciones municipales de junio de 1987. La transcripción es fiel a la estructura de dicho espacio electoral, donde Juan Barranco intervenía en tres ocasiones mientras que Pascual Maragall lo hacia en tan sólo dos. Dichas intervenciones se sucedieron alternativamente.

\section{Discurso de Juan Barranco}

Aquella situación de desidia, de abandono, de deterioro y de especulación está siendo sustituida ya en este momento - ha sido sustituida- por una política de respeto, de recuperación, de rehabilitación. De recuperación de nuestra memoria histórica, de nuestras costumbres, de nuestras raices, de nuestro casticismo. De recuperación y de rehabilitación de las casas y de las fachadas del Madrid de los Austrias, del Madrid de Galdós, de Mesonero Romanos, de Arniches, de Larra, de Lope de Vega. Este Madrid que ha merecido la atención y el respeto, la curiosidad internacional por este esfuerzo de rehabilitación y de recuperación. Este Madrid que nos ha llevado, gracias al prestigio internacional, a que en estos momentos ostentemos la presidencia de la Unión de Capitales Europeas. Este es el Madrid por el que estamos trabajando todos. Este es el Madrid que queremos.

\section{Discurso de Pascual Maragall}

En urbanismo, creo modestamente que en esta ciudad se están haciendo cosas ejemplares. Estamos ganando terreno para la ciudad, recuperando las antiguas instalaciones ferroviarias, los cuarteles e incluso antiguas fábricas para poner en ellas zonas verdes y parques -quince hemos hecho nuevosque a esta ciudad le hacían falta como el pan que come.

Barcelona es una de las ciudades más densas de Europa, como es bien sabido. En el corazón de la ciudad, en el Raval, en la Barcelona vieja, vamos a construir la Casa de la Caridad, el Museo de Arte Contemporáneo más avanzado de España. Y al otro lado de la ciudad, en Felipe II Vaig de Roda, en la frontera entre los antiguos barrios de Sant Andreu y San Martín, estamos haciendo un puente que es una obra de arte y que demuestra que la ingeniería no está reñida con la estética. Aquí debajo mismo vamos a hacer pasar el cinturón litoral, que junto con el segundo cinturón completan la ronda que está aprobada desde 1962 para descongestionar el tráfico de la ciudad y que nadie había tenido hasta ahora fuerza para construir. Ya luego en el Ensanche, que todos conocen, estamos consiguiendo la «nueva frontera", que es recuperar los interiores de manzana de forma que los par- 
ques, que el urbanismo no permitía conseguir, se consigan entre casa y casa. Se trabaja aquí con imaginación, los mejores arquitectos y técnicos del mundo nos ayudan.

\section{Discurso de Juan Barranco (2." parte)}

En 1979 se inició uno de los periodos más profundos de transformación y de cambio de la ciudad de Madrid. De 1983 a 1987 han sido los cuatro años, sin duda alguna, de mayor capacidad creativa y de los períodos más fecundos de la historia cultural y creativa de la ciudad de Madrid. Ahí están también a la vista de todo el mundo el esfuerzo de gestión que se ha hecho en los últimos cuatro años. Ahí está, por ejemplo, este río Manzanares, limpio, sano, recobrado, recuperado como zona de recreo para todos los madrileños. Los cincuenta mil millones de pesetas que hemos invertido en obra nueva a lo largo y a lo ancho de todos los barrios y de todos los distritos de la ciudad de Madrid. Más de cuarenta centros para la tercera edad y para la juventud; más de veintiún polideportivos nuevos, doscientas once hectáreas de parques y jardines nuevos, hechos y puestos para el disfrute de todos los madrileños en todos los barrios y en todos los distritos. Una gestión que se ha hecho en los últimos años por primera vez en la historia de nuestro ayuntamiento sin déficit. Una gestión con hombres con experiencia, con un equipo que encabezó Tierno Galván y con una labor que queremos continuar a partir de este año de 1987 . Yo creo que con mirar las cosas con serenidad, con sensatez y con objetividad se puede apreciar esta obra, es ese trabajo, ese fruto de nuestra gestión que está a la vista de todos aquellos hombres y mujeres, de todos los vecinos de Madrid que quieran reflexionar y ver la realidad con objetividad y con serenidad.

\section{Discurso de Pascual Maragall (2." parte)}

Barcelona ha sido siempre una ciudad abierta a Europa y América. Nuestra tradición comercial, económica, pero también la artística, la de las atarazanas góticas, la del modernismo de Puig y Calafall y de Gaudí, asi lo testimonian. Nosotros en los últimos años hemos estado trabajando para que esta tradición no se perdiera ni en el campo comercial, ni en el campo económico, ni tampoco en el campo cultural. Y creo que lo hemos estado consiguiendo, como otras ciudades españolas también lo están consiguiendo. Mi amigo Manolo del Valle, alcalde socialista de Sevilla, está poniendo a Sevilla en el 92 de la mejor manera. Lo mismo ocurre con nosotros: en el horizonte 92 está para nosotros el reencuentro de una tradición y es al 
mismo tiempo, una apuesta de futuro. Yo creo que trabajando juntos, ciudadanos y ayuntamiento, lo conseguiremos. Haciendo las cosas bien hechas, ganaremos el futuro.

\section{Discurso de Juan Barranco (3." parte)}

Madrid es una ciudad con un gran futuro. El trabajo que se ha realizado en estos últimos años y los proyectos de futuro que ya están en marcha en estos momentos, nos permiten asegurar con confianza que esta ciudad tiene un futuro formidable. Madrid quiere ser y va a ser en 1992 la capital cultural de Europa. En ese año nos vamos a convertir en el gran escenario, no sólo de la cultura europea sino de la cultura mundial. Esta ciudad, que es una ciudad llena de vitalidad, de vitalidad creadora en el mundo del arte, de la cultura, va a ser también, gracias a esos proyectos, una ciudad con vitalidad económica, llena de riqueza, de una riqueza de la que nos vamos a beneficiar todos los madrileños, todos los barrios, todos los distritos de Madrid.

$Y$ esta es la gran ilusión y la gran confianza que yo quiero transmitirles a todos ustedes. La ilusión y la confianza que yo tengo en esta ciudad, en el futuro de Madrid. Y lo que me gustaría transmitirles, lo que me gustaría contagiarles a todos ustedes es esa ilusión y esa confianza para que todos los madrileños participen en la construcción del futuro de la ciudad de Madrid. Para que todos los vecinos, el día de mañana, podamos sentirnos legítimamente orgullosos de haber construido una ciudad más próspera, una ciudad más joven, una ciudad para el respeto, una ciudad para la convivencia, y sobre todo, una ciudad para la paz. 